\title{
Pulmonary gas exchange in hereditary hemorrhagic telangiectasia patients with liver arteriovenous malformations
}

\author{
Carole de Picciotto ${ }^{1,2}$, Mostafa El Hajjam ${ }^{3,2}$, Carma Karam ${ }^{4,2}$, Thierry Chinet ${ }^{5,2}$ and Marcel Bonay ${ }^{1,2^{*}}$ (D)
}

\begin{abstract}
Background: The severity of Hereditary Hemorrhagic Telangiectasia (HHT) disease is generally related to vascular visceral involvement represented by arteriovenous malformations (AVMs). Pulmonary function tests (PFTs) remain normal in HHT patients without Pulmonary AVMs (PAVMs) and respiratory comorbidity. The aim of our study was to compare the diffusing capacity of the lung for carbon monoxide $\left(D_{\llcorner C O}\right)$ and nitric oxide $\left(D_{\llcorner N O}\right)$ and its 2 components: the pulmonary capillary blood volume (Vc) and the alveolar-capillary membrane conductance (Dm), in HHT patients with PAVMs, PAVMs and liver AVMs (LAVMs), LAVMs without PAVM, no PAVM and LAVM, and controls.

Methods: Sixty one consecutive adult patients (HHT without PAVM and LAVM: $n=7 ;$ HHT with PAVMs: $n=8 ;$ HHT with PAVMs and LAVMs: $n=25$; HHT with LAVMs: $n=21$ ) and controls matched for age and sex ratio without respiratory, heart and liver pathology ( $n=15)$ were non-invasively evaluated using PFTs, combined $D_{\mathrm{LCO}} / \mathrm{D}_{\mathrm{LNO}}$, arterial blood gas at rest, contrast echocardiography and enhanced computed tomography scan of the liver and chest the day of pulmonary function testing.
\end{abstract}

Results: We found that patients with LAVMs but without PAVMs exhibited increased Vc/Dm ratio. Interestingly, HHT patients with hepatic artery enlargement showed higher Vc/Dm ratio than HHT patients with normal hepatic artery diameter.

Conclusion: $\mathrm{Vc} / \mathrm{Dm}$ ratio may have practical impact in HHT patients' management to detect precociously the occurrence of LVAMs. However, further studies are needed to assess the accuracy and potential prognostic value of pulmonary gas exchange measurements in HHT patients with LVAMs.

Keywords: Pulmonary diffusing capacity, Arteriovenous malformations, Hereditary hemorrhagic telangiectasia, Computed tomography scan of the liver and chest, Echocardiography

\section{Introduction}

The severity of Hereditary Hemorrhagic Telangiectasia (HHT) or Rendu-Osler-Weber disease is generally related to vascular visceral involvement represented by arteriovenous malformations (AVMs). Mutations in the endoglin (ENG) gene, the activin A receptor type II-like 1 (ACVRL1/ALK1) gene, and infrequently, the SMAD4

\footnotetext{
*Correspondence: marcel.bonay@aphp.fr

${ }^{1}$ Service de Physiologie-Explorations Fonctionnelles Hôpital Ambroise Paré Assistance Publique-Hôpitaux de Paris (AP-HP) Boulogne, France et Université de Versailles Saint Quentin (UVSQ), 92104 Boulogne cedex, Boulogne, France ${ }^{2}$ HHT center Hôpital Ambroise Paré Assistance Publique-Hôpitaux de Paris (AP-HP) Boulogne, France et Université de Versailles Saint Quentin (UVSQ), Boulogne, France

Full list of author information is available at the end of the article
}

gene are responsible for HHT disease [1]. Pulmonary AVMs (PAVMs) induce right-to-left shunting, which is routinely assessed by contrast echocardiography and arterial blood gas measurements. Pulmonary functions test (PFTs), completed concomitantly with arterial blood gas measurements, remain normal in HHT patients without PAVMs and respiratory comorbidity [2]. Nevertheless, few studies have evaluated pulmonary gas exchange in HHT patients. The combined diffusing capacity of the lung for carbon monoxide $\left(\mathrm{D}_{\mathrm{LCO}}\right)$ and nitric oxide $\left(D_{\mathrm{LNO}}\right)$ is a simple test that allows the determination of 2 components of pulmonary gas exchange: the pulmonary capillary blood volume (Vc) and the alveolarcapillary membrane conductance (Dm) [3]. 
The aim of our study was to compare diffusing capacity of the lung for carbon monoxide $\left(\mathrm{D}_{\mathrm{LCO}}\right)$ and nitric oxide $\left(\mathrm{D}_{\mathrm{LNO}}\right)$ and its 2 components Dm and Vc, in HHT patients with PAVMs, PAVMs and liver AVMs (LAVMs), LAVMs without PAVM, no PAVM and LAVM, and controls.

\section{Methods}

To be included in the study, patients had to fulfill the following criteria: (1) diagnosis of HHT ascertained by identification of an ENG, ACVRL1/ALK1, or SMAD4 mutation and/or by the presence of at least three Curaçao criteria (nose bleeds, mucocutaneous telangiectasia, visceral arteriovenous malformations, and family history) and (2) age $>18$ years. Patients were not included if they were suffering from respiratory or cardiac conditions unrelated to HHT. Sixty one consecutive adult patients with forced expiratory volume in one second/vital capacity ratio $>70 \%$ (HHT without PAVM and LAVM: $n=$ 7; HHT with PAVMs: $n=8$; HHT with PAVMs and LAVMs: $n=25$; HHT with LAVMs: $n=21$ ) and controls matched for age and sex ratio without respiratory, heart and liver pathology $(n=15)$ were non-invasively evaluated, using PFTs, combined $\mathrm{D}_{\mathrm{LCO}} / \mathrm{D}_{\mathrm{LNO}}$, arterial blood gas at rest, contrast echocardiography and enhanced computed tomography scan of the liver and chest the day of pulmonary function testing (Table 1).

Lung volumes were measured with a PFT-Masterscreen apparatus (Jaeger, CareFusion, Hoechberg, Germany). PFTs included measurements of functional residual capacity (FRC) by the helium dilution method and calculation of total lung capacity (TLC), measurements of vital capacity ( $\mathrm{VC})$ and forced expiratory volume in $1 \mathrm{~s}\left(\mathrm{FEV}_{1}\right)$. Arterial blood sampling was made with patients in the sitting position. Blood sample was analyzed for $\mathrm{pO}_{2}, \mathrm{pCO}_{2}$, $\mathrm{pH}$ and hemoglobin concentration (Rapidlab 1245, Siemens Healthcare Diagnostics Inc., Tarrytown, NY, USA).

Simultaneous measurements of $\mathrm{D}_{\mathrm{LNO}}, \mathrm{D}_{\mathrm{LCO}}$ and $\mathrm{V}_{\mathrm{A}}$ were performed using the single-breath method (MasterScreen $^{\text {Ti }}$ PFT Pro, Jaeger, CareFusion, Hoechberg, Germany). Hemoglobin level ( $\mathrm{Hb})$ was measured in the patients and $\mathrm{D}_{\mathrm{LCO}}$ was corrected to the standard $\mathrm{Hb}$ according to international guidelines $[3,4]$. Dm was expressed as $\mathrm{D}_{\mathrm{LNO}}$ divided by 1.97 [5], and Vc was derived as previously described [6].

Systolic pulmonary artery pressure (sPAP) was noninvasively assessed by Doppler echocardiography (Siemens/Sequoia Acuson C512 system (Acuson, Mountain View, CA, USA) or Vivid E9 (GE Medical Systems, Horten, Norway) from tricuspid regurgitation using the modified Bernoulli equation [7]. Left ventricular ejection fraction was calculated by the method of Teichholz.

Computed tomography scan of the liver and chest were performed by using a 16-detector row helical CT scanner (Mx 8000 IDT; Philips Healthcare, Best, the Netherlands). Pulmonary involvement (identification of pulmonary AVMs) and hepatic involvement (dilatation of the hepatic artery $>6 \mathrm{~mm}$, telangiectasia, or vascular confluent masses or intrahepatic vascular shunts) were recorded. The diameter of the common hepatic artery was measured $1 \mathrm{~cm}$ before the origin of the gastroduodenal artery [8].

Institutional review board approval was obtained for this study (CEPRO 2014-047). Statistical analyses were

Table 1 Characteristics of the study populations

\begin{tabular}{|c|c|c|c|c|c|}
\hline & Controls & $\mathrm{HHT}$ & PAVMs & $P+$ LAVMs & LAVMs \\
\hline$n$ & 15 & 7 & 8 & 25 & 21 \\
\hline Age, yr. ${ }^{a}$ & $46(23 ; 53)$ & $27(18 ; 59)$ & $40(35 ; 51.75)$ & $36(29 ; 47)$ & $43.7(32.5 ; 55.5)$ \\
\hline Female/Male ratio ${ }^{a}$ & $10 / 5$ & $2 / 5$ & $4 / 4$ & $16 / 9$ & $17 / 4$ \\
\hline LVEF, $\%^{\text {a }}$ & nd & $69(61 ; 73)$ & $63(61.5 ; 71.75)$ & $70(67 ; 76)$ & $71(68.5 ; 75.5)$ \\
\hline$(\mathrm{A}-\mathrm{a}) \mathrm{O}_{2}{ }^{\mathrm{a}}(\mathrm{kPa})$ & nd & $1.25(0 ; 2.92)$ & $2(1.5 ; 2.85)$ & $2(0.5 ; 3.7)$ & $1.15(0.5 ; 1.75)$ \\
\hline $\mathrm{Hb}, \mathrm{g} / \mathrm{dL}^{\mathrm{a}}$ & nd & $14.9(14.5 ; 15.1)$ & $14.55(13.8 ; 15.2)$ & $14.2(13.5 ; 15)$ & $14(12.1 ; 14.7)$ \\
\hline $\mathrm{TLC}, \%^{\mathrm{a}}$ & $93.8(90 ; 100)$ & $99(90 ; 102)$ & $104.5(99.25 ; 113)$ & $104(94.5 ; 111.5)$ & $101(91 ; 117.5)$ \\
\hline $\mathrm{DLCO}, \%^{\mathrm{a}}$ & $88.5(85 ; 92.8)$ & $85(80 ; 97)$ & $104(91.75 ; 110)$ & $81(74.5 ; 86.5)$ & $91(79.5 ; 98.5)$ \\
\hline DLCO $/ \mathrm{A}, \%^{\mathrm{a}}$ & $95.2(90.6 ; 112.9)$ & $98(92.5 ; 102.5)$ & $100(78 ; 111)$ & $88(81 ; 95)$ & $94(86.25 ; 104)$ \\
\hline$D_{\mathrm{LNO}} / \mathrm{D}_{\mathrm{LCO}}$ & $4.1(3.8 ; 4.3)$ & $4.5(4.3 ; 4.7) \#$ & $4.3(4.2 ; 4.6)$ & $4.5(4.25 ; 4.6) \#$ & $4.3(3.95 ; 4.5)$ \\
\hline$V_{c}, \%^{a}$ & $85(76.7 ; 91.9)$ & $85(79 ; 93)$ & $103.5(94.25 ; 110.8)$ & $78(73 ; 89)$ & $94(79 ; 97)$ \\
\hline $\mathrm{Dm}, \%^{\mathrm{a}}$ & $125.5(120.7 ; 139.2)$ & $113(102 ; 119)$ & $135.5(129.3 ; 147.3)$ & $107(98.5 ; 116)$ & $117(100 ; 125.5)$ \\
\hline Vc/Dm ratio & $1.09(1.01 ; 1.2)$ & $1.15(1.13 ; 1.25)$ & $1.21(1.12 ; 1.26)$ & $1.16(1.11 ; 1.42)$ & $1.35(1.18 ; 1.62)^{b}$ \\
\hline
\end{tabular}

Values given as median (25\%;75\% quartiles), ${ }^{a}$ no difference between groups; ${ }^{\mathrm{b}}: p<0.05$ vs other groups; \# $p=0.01$ vs controls; HHT Hereditary Hemorrhagic Telangiectasia patients without arteriovenous malformations, PAVMs pulmonary arteriovenous malformations, $P+L A V M s$ Pulmonary+Liver arteriovenous malformations, LAVMs Liver arteriovenous malformations. LVEF left ventricular ejection fraction, $(A-a) \mathrm{O}_{2}$ alveolar-arterial $\mathrm{O}_{2}$ difference at rest, $\mathrm{Hb}$ hemoglobin level $\mathrm{g} / \mathrm{dL}, T L C, \%$ total lung capacity, \% predicted, $D_{L C O}$ diffusing capacity of the lung for carbon monoxide, $D_{L C O} N_{A}$ transfer coefficient for carbon monoxide, $V C$ pulmonary capillary blood volume, $D m$ alveolar-capillary membrane conductance, $D_{L N O} / D_{L C O}$ diffusing capacity of the lung for nitric oxide/ $D_{L C O}$ ratio 
performed using GraphPad Prism 5.01 for Windows (GraphPad Software, San Diego California). Betweengroup differences were first assessed using analysis of variance with Bonferroni correction for multiple comparisons followed by post-hoc Mann-Whitney test. Results were reported as the median and 25 and $75 \%$ quartiles. A $p$ value $<0.05$ was considered statistically significant.

\section{Results}

Total lung capacity, alveolar-arterial $\mathrm{O}_{2}$ difference at rest, hemoglobin level, $\mathrm{D}_{\mathrm{LCO}}$, transfer coefficient for carbon monoxide $\left(\mathrm{D}_{\mathrm{LCO}} / \mathrm{V}_{\mathrm{A}}\right)$, Vc and Dm (\% predicted) did not differ between groups (Table 1). Assuming that $D_{\text {LNO }}$ represents the alveolar membrane component of gas transfer, and that $\mathrm{D}_{\mathrm{LCO}}$ depends on $\mathrm{Dm}$, Vc, hemoglobin concentration and pulmonary capillary oxygen tension, the $\mathrm{D}_{\mathrm{LNO}} / \mathrm{D}_{\mathrm{LCO}}$ ratio might differ between patients with alveolocapillary membrane modifications and patients with microvascular disease. $\mathrm{D}_{\mathrm{LNO}} / \mathrm{D}_{\mathrm{LCO}}$ ratio was increased in HHT patients $(p=0.01)$ and in $\mathrm{P}+$ LAVM patients $(p=0.01)$ versus controls but did not differ between patients groups (Table 1). Vc scaled by $\mathrm{Dm}(\mathrm{Vc} / \mathrm{Dm}$ ratio), which is used to assess the functional efficiency of the alveolar-capillary membrane, was increased ( $p<0.05$ for all) in LAVMs as compared to other groups (Table 1). When a cut-off value of $6.5 \mathrm{~mm}$ diameter was used to establish common hepatic artery enlargement [8], HHT patients with hepatic artery enlargement (diameter $>6.5 \mathrm{~mm}$ ) showed higher $\mathrm{Vc} / \mathrm{Dm}$ ratio than HHT patients with hepatic artery diameter $\leq$ $6.5 \mathrm{~mm}(1.25$ (1.15;1.50), $n=32$ vs $1.16(1.10 ; 1.30), n=$ 29; $p=0.03$ ) (Fig. 1a). Vc/Dm ratio was decreased in HHT patients with low systolic pulmonary artery pressure $<37 \mathrm{mmHg}$, a cut-off value associated with no indirect echographic signs of pulmonary hypertension [9], as compared to HHT patients with high systolic pulmonary artery pressure $\geq 37 \mathrm{mmHg}(1.18(1.12 ; 1.35), n=54$ vs $1.40(1.38 ; 1.95), n=7 ; p<0.01)$ (Fig. 1b).

\section{Discussion}

Our results suggest that pulmonary gas exchanges are modified in HHT patients with LAVMs. More specifically, we found that patients with LAVMs but without PAVMs exhibited increased Vc/Dm ratio.

A small decrease in the transfer coefficient for carbon monoxide $\left(\mathrm{D}_{\mathrm{LCO}} / \mathrm{V}_{\mathrm{A}}\right)$ has been reported in HHT patients in some studies $[10,11]$. However, the effect of HHT on 2 components of pulmonary gas exchange Vc and Dm was not determined and comparisons between patients with or without arteriovenous malformations and controls were not done. In our study, we found no difference in the diffusing capacity of the lung for carbon
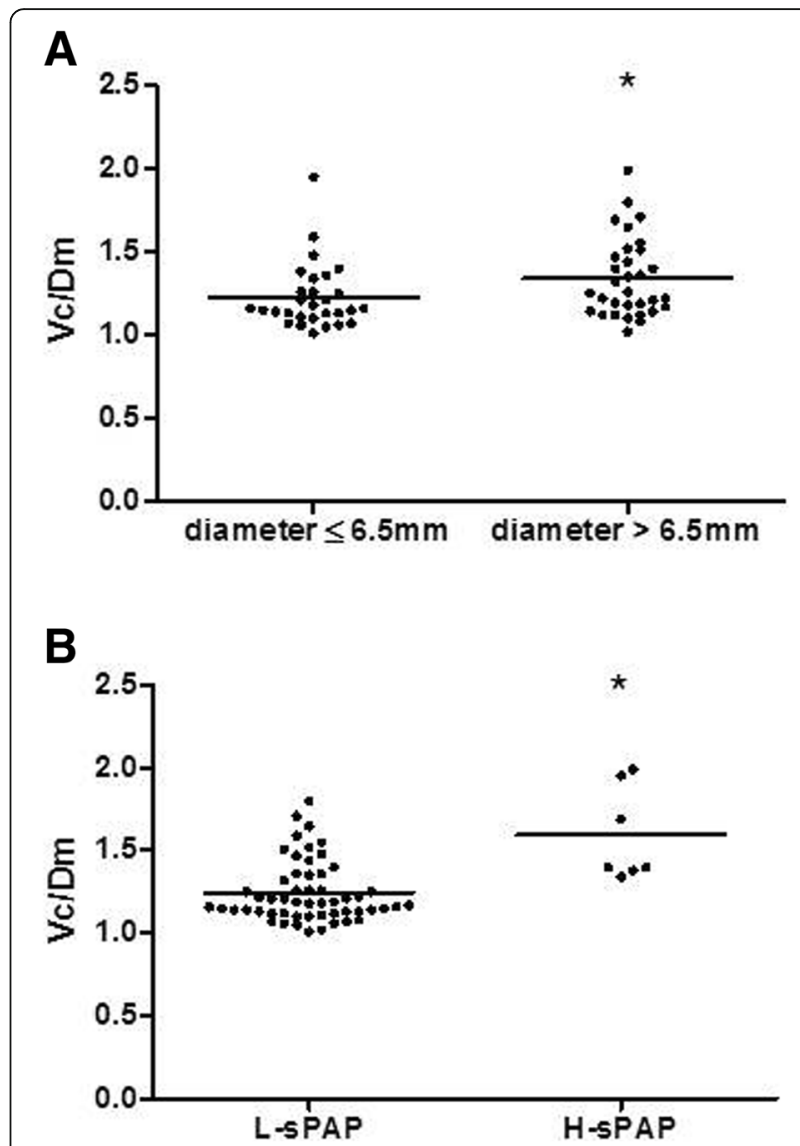

Fig. 1 a Pulmonary capillary blood volume/alveolo-capillary membrane conductance ratio (Vc/Dm) was increased in Hereditary Hemorrhagic Telangiectasia (HHT) patients with hepatic artery diameter > $6.5 \mathrm{~mm}$ vs HHT patients with hepatic artery diameter $\leq$ $6.5 \mathrm{~mm}$, $p=0.03$; b Pulmonary capillary blood volume/alveolocapillary membrane conductance ratio (Vc/Dm) was increased in Hereditary Hemorrhagic Telangiectasia (HHT) patients with high systolic pulmonary artery pressure $(\mathrm{H}-\mathrm{sPAP} \geq 37 \mathrm{mmHg})$ vs HHT patients with low sPAP $(\mathrm{L}-\mathrm{sPAP}<37 \mathrm{mmHg})$ and controls, ${ }^{*} p<0.01$

monoxide in HHT patients with or without arteriovenous malformations and in control patients.

The mechanism involved in the increase in the $\mathrm{Vc} / \mathrm{Dm}$ ratio in HHT patients with LAVMs has not been clearly defined. Left ventricular ejection fraction obtained by echocardiography was normal in our study population, but cardiac output was not systematically measured. Interestingly, in a recent work, low $\mathrm{Dm} / \mathrm{Vc}$ ratio was associated with failure to achieve the high cardiac output of hyperdynamic state of obesity [12]. The possible increased pulmonary blood flow secondary to the increased cardiac output state associated with LAVMs in HHT patients might contribute to the high $\mathrm{Vc} / \mathrm{Dm}$ ratio. The higher $\mathrm{Vc} /$ Dm ratio found in HHT patients with hepatic artery enlargement fits well with this hypothesis as a cut-off value of $6.5 \mathrm{~mm}$ diameter was used to establish common hepatic artery enlargement and hepatic involvement in HHT [8]. 
In our study, Vc/Dm ratio was increased in HHT patients with high systolic pulmonary artery pressure. Increased pulmonary capillary blood volume secondary to increased pulmonary pressure observed in heart failure is unlikely because left ventricular ejection fraction assessed by echocardiography was normal in our study population. Interestingly, one study reported a significant correlation between systolic pulmonary artery pressure and $\mathrm{Vc} / \mathrm{Dm}$ ratio in patients with chronic infiltrative lung disease and controls [13]. Pulmonary hypertension may develop in HHT patients as a consequence of high output cardiac failure associated with LVAMs [14]. Although right heart catheterization measurements taken as a gold standard were not completed in our study population, transthoracic echocardiography Doppler allows for accurate measurements of the pulmonary circulation [9]. Unfortunately, cardiac output was not systematically measured to detect high output cardiac failure in our patients.

The main result of this work is that patients with isolated liver arteriovenous malformations (LAVMs) display an increased pulmonary capillary blood volume over alveolar-capillary membrane conductance ratio $(\mathrm{Vc} / \mathrm{Dm})$, which may be due to higher cardiac output. However, some limitations should be highlighted. First, right heart catheterization was not done and cardiac output was not systematically measured. Further studies including these measurements are needed to confirm that high pulmonary blood flow, secondary to increased cardiac output, might contribute to the increase in the $\mathrm{Vc} / \mathrm{Dm}$ ratio in LAVMs patients. Secondly, the Vc/Dm ratio was not increased in patients with liver and pulmonary arteriovenous malformations (P + LAVMs). Different haemodynamic profiles have been described in LAVMs and P + LAVMs patients [15]. However, the mechanisms of these cardiovascular modifications and their consequences on pulmonary circulation and gas exchange are not fully understood.

\section{Conclusions}

LVAMs may alter pulmonary gas exchange in HHT patients as reflected by the increase in the $\mathrm{Vc} / \mathrm{Dm}$ ratio, which is possibly induced by the increase in the cardiac output. This pulmonary gas exchange alteration may have practical impact in HHT patients' management. Indeed, as combined $\mathrm{D}_{\mathrm{LCO}} / \mathrm{D}_{\mathrm{LNO}}$ assessment is simple and inexpensive, this test may be used for fine follow-up of HHT patients to detect precociously the occurrence of LVAMs. However, further studies are needed to assess the accuracy and potential prognostic value of pulmonary gas exchange measurements in HHT patients with LVAMs as compared with right heart catheterization measurements and computed tomography scan of the liver and chest.

\section{Abbreviations}

AVMs: Arteriovenous malformations; $D_{L c o}$ : Diffusing capacity of the lung for carbon monoxide; $\mathrm{D}_{\mathrm{LCO}} \mathrm{N}_{\mathrm{A}}$ : Transfer coefficient for carbon monoxide; $D_{\llcorner N O}$ : Diffusing capacity of the lung for nitric oxide; Dm: Alveolo-capillary membrane conductance; HHT: Hereditary Hemorrhagic Telangiectasia; LAVMs: Liver AVMs; PAVMs: Pulmonary AVMs; PFTs: Pulmonary function tests; SPAP: Systolic pulmonary artery pressure; Vc: Pulmonary capillary blood volume

\section{Acknowledgements}

The authors acknowledge the members of the multidisciplinary team dedicated to patients with HHT of Ambroise Paré Hospital.

\section{Authors' contributions}

MB initiated the study and supervised data collection, data analysis and writing of the manuscript. MB and CdP contributed to the study concept and design. TC, MEH, CK and CdP participated in data collection and in revision of the manuscript. All authors read, provided input, and gave final approval the version to be published.

\section{Funding}

Not applicable.

\section{Availability of data and materials}

The authors declare that the data supporting the findings of this study are available within the article.

Ethics approval and consent to participate

Approval for the study was obtained from the Institutional Review Board of the French Learned Society for Respiratory Medicine ( $n^{\circ}$ 2014-047).

\section{Consent for publication}

Not applicable.

\section{Competing interests}

The authors declare that they have no competing interests.

\section{Author details}

${ }^{1}$ Service de Physiologie-Explorations Fonctionnelles Hôpital Ambroise Paré Assistance Publique-Hôpitaux de Paris (AP-HP) Boulogne, France et Université de Versailles Saint Quentin (UVSQ), 92104 Boulogne cedex, Boulogne, France. ${ }^{2}$ HHT center Hôpital Ambroise Paré Assistance Publique-Hôpitaux de Paris (AP-HP) Boulogne, France et Université de Versailles Saint Quentin (UVSQ), Boulogne, France. ${ }^{3}$ Service de Radiologie Hôpital Ambroise Paré Assistance Publique-Hôpitaux de Paris (AP-HP) Boulogne, France et Université de Versailles Saint Quentin (UVSQ), Boulogne, France. ${ }^{4}$ Service de Cardiologie Hôpital Ambroise Paré Assistance Publique-Hôpitaux de Paris (AP-HP) Boulogne, France et Université de Versailles Saint Quentin (UVSQ), Boulogne, France. ${ }^{5}$ Service de Pneumologie Hôpital Ambroise Paré Assistance Publique-Hôpitaux de Paris (AP-HP) Boulogne, France et Université de Versailles Saint Quentin (UVSQ), Boulogne, France.

Received: 27 February 2019 Accepted: 20 June 2019

Published online: 04 July 2019

\section{References}

1. McDonald J, Wooderchak-Donahue W, VanSant Webb C, Whitehead K, Stevenson DA, Bayrak-Toydemir P. Hereditary hemorrhagic telangiectasia: genetics and molecular diagnostics in a new era. Front Genet. 2015;6:1.

2. Rotenberg C, Bonay M, El Hajjam M, et al. Effect of pulmonary arteriovenous malformations on the mechanical properties of the lungs. BMC Pulm Med. 2017;17(1):64.

3. Zavorsky GS, Hsia CC, Hughes JM, et al. Standardisation and application of the single-breath determination of nitric oxide uptake in the lung. Eur Respir J. 2017:49:1600962.

4. Maclntyre N, Crapo RO, Viegi G, et al. Standardisation of the single-breath determination of carbon monoxide uptake in the lung. Eur Respir J. 2005;26: $720-35$.

5. Aguilaniu B, Maitre J, Glenet S, et al. European reference equations for CO and NO lung transfer. Eur Respir J. 2008;31:1091-7. 
6. Guenard H, Varene N, Vaida P. Determination of lung capillary blood volume and membrane diffusing capacity in man by the measurements of NO and CO transfer. Respir Physiol. 1987;70:113-20.

7. Quinones MA, Otto CM, Stoddard M, et al. Recommendations for quantification of Doppler echocardiography: a report from the Doppler quantification task force of the nomenclature and standards Committee of the American Society of echocardiography. J Am Soc Echocardiogr. 2002;15: 167-84.

8. Barral M, Sirol M, Placé V, et al. Hepatic and pancreatic involvement in hereditary hemorrhagic telangiectasia: quantitative and qualitative evaluation with 64-section CT in asymptomatic adult patients. Eur Radiol. 2012;22:161-70

9. D'Alto M, Romeo E, Argiento P, et al. Accuracy and precision of echocardiography versus right heart catheterization for the assessment of pulmonary hypertension. Int J Cardiol. 2013;168:4058-62.

10. Dutton JA, Jackson JE, Hughes JM, et al. Pulmonary arteriovenous malformations: results of treatment with coil embolization in 53 patients. AJR Am J Roentgenol. 1995;165:1119-25.

11. Gupta P, Mordin C, Curtis J, Hughes JM, Shovlin CL, Jackson JE. Pulmonary arteriovenous malformations: effect of embolization on right-to-left shunt, hypoxemia, and exercise tolerance in 66 patients. AJR Am J Roentgenol. 2002:179:347-55

12. Oppenheimer BW, Berger Kl, Ali S, et al. Pulmonary vascular congestion: a mechanism for distal lung unit dysfunction in obesity. PLoS One. 2016;11: e0152769.

13. Bonay M, Bancal C, de Zuttere D, Arnoult F, Saumon G, Camus F. Normal pulmonary capillary blood volume in patients with chronic infiltrative lung disease and high pulmonary artery pressure. Chest. 2004;1265:1460-6.

14. Roman BL, Cuttica MJ. Classifying pulmonary hypertension in hereditary hemorrhagic telangiectasia. Hemodynamics matter. Am J Respir Crit Care Med. 2017;196:1244-6.

15. Revuz S, Decullier E, Ginon I, et al. Pulmonary hypertension subtypes associated with hereditary haemorrhagic telangiectasia: Haemodynamic profiles and survival probability. PLoS One. 2017;12(10):e0184227.

\section{Publisher's Note}

Springer Nature remains neutral with regard to jurisdictional claims in published maps and institutional affiliations.

Ready to submit your research? Choose BMC and benefit from:

- fast, convenient online submission

- thorough peer review by experienced researchers in your field

- rapid publication on acceptance

- support for research data, including large and complex data types

- gold Open Access which fosters wider collaboration and increased citations

- maximum visibility for your research: over $100 \mathrm{M}$ website views per year

At $\mathrm{BMC}$, research is always in progress.

Learn more biomedcentral.com/submissions 